\title{
Pelvic-Peritoneal Tuberculosis with Elevated Serum and Peritoneal Fluid Ca-125 Levels
}

A Report of Two Cases
\begin{tabular}{|l|l|l|}
\hline T. & Timur & Gürgan \\
\hline H. & Hulusi & Zeyneloğlu \\
\hline B. & Bülent & Urman \\
\hline O. & Osman & Develioğlu \\
\hline H. & Hakan & Yarali \\
\hline
\end{tabular}

Hacettepe University, Faculty of Medicine, Department of Obstetrics and Gynecology, Division of Reproductive Endocrinology and Infertility, Ankara, Turkey

\section{Key Words}

Tuberculosis

Pelvic tuberculosis

Ca-125

\section{Abstract}

We report 2 patients with pelvic-peritoneal tuberculosis and elevated serum and peritoneal fluid levels of Ca-125. The first was a young and infertile women who had cul-de-sac nodularity and dysmenorrhea. The other was postmenopausal and presented with weight loss and ascites. While a preoperative diagnosis of endometriosis was made in the former, intraperitoneal malignancy was considered in the latter. The diagnosis of pelvic-peritoneal tuberculosis was reached by laparoscopic-directed biopsy in both patients. Serum levels of Ca-125 returned to normal limits following antituberculous drug treatment.

Timur Gürgan, MD, Hacettepe University, Faculty of Medicine, Department of Obstetrics and Gynecology Sihhiye, 06100 Ankara (Turkey)

Introduction

Elevated serum Ca-125 levels have been previously reported in patients with pelvic-peritoneal tuberculosis [1]. Given the high prevalence of tuberculosis in developing countries, this finding may have importance related to the differential diagnosis of pelvic masses when the presumptive diagnoses include genital malignancy or endometriosis. We herein report elevated Ca-125 levels in 2 patients with pelvic-peritoneal tuberculosis; one presenting with infertility and an adnexal mass and the other with postmenopausal ascites.

Case Reports

\section{Case 1}

H.M., 27 years old, presented with a 1-year history of primary infertility. She had regular menstrual cycles with dysmenorrhea. Her past history was insignificant. Her sister had been treated for pulmonary tuberculosis 5 years ago. The physical examination showed no abnormality. Bimanual pelvic examination revealed cul-de-sac nodularity and fullness in the left adnexal area. Hysterosalpingography demonstrated bilateral proximal ampullary occlusion. The remainder of the infertility work-up was unremarkable. A diagnostic laparoscopy was undertaken which showed multiple small, white granulomatous lesions (3-5 $\mathrm{mm}$ in diameter) on the uterus, adnexa and intestinal loops. Both fallopian tubes 
were occluded in their proximal ampullary portions. There were dense and vascular adhesions between the ovaries, fallopian tubes, and the pelvic side wall. Multiple lesional biopsies were obtained and the clear and yellowish peritoneal fluid which was approximately $50 \mathrm{~cm} 3$ in volume was aspirated. A dilatation and curettage was performed and the material was sent for histological examination. Blood was obtained by venipuncture for assessment of the serum Ca125 level (Immunoradiometric assay, ELSA-CA 125, Compagnie ORIS Industrie, Yvette, France). A tuberculin test was performed postopera-tively which showed an induration of $10 \mathrm{~mm}$ in diameter.

Microscopic examination of the peritoneal fluid was negative for bacteria and acid-fast bacilli. Peritoneal fluid glucose, lactate dehy-drogenase, adenosine diaminase, and total protein concentrations were $101 \mathrm{mg} / \mathrm{ml}, 170 \mathrm{U} / \mathrm{ml}, 94 \mathrm{IU} / \mathrm{ml}$ and $6.0 \mathrm{~g} / \mathrm{dl}$, respectively. Culture on Lowenstein-Jensen media did not show any growth. Histological examination of the biopsy material was consistent with tuberculosis which showed granulomatous inflammation with epitheloid cells, Langhans-type giant cells, and peripheral lymphocytic infiltration (fig. 1). Dilatation and curettage specimen showed nonspecific

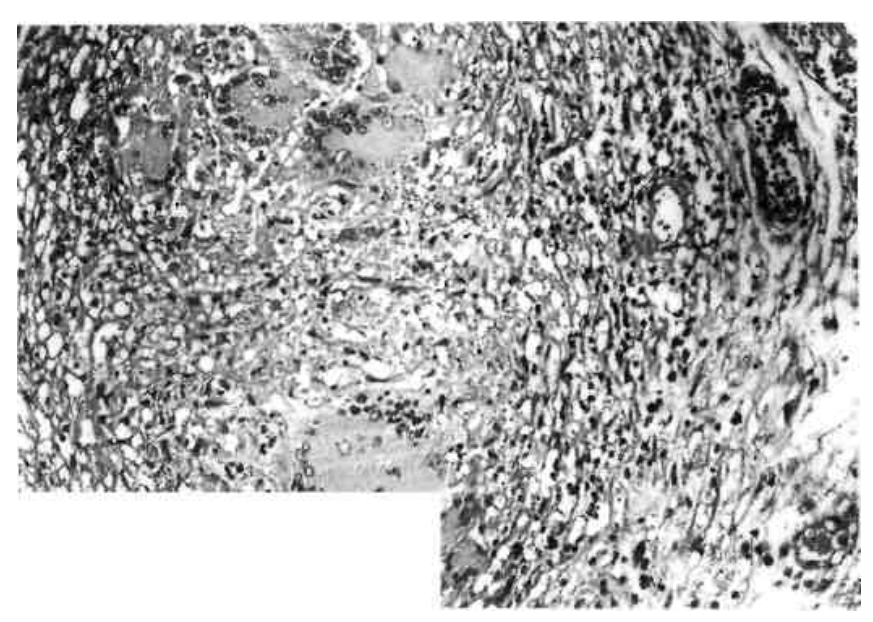

endometritis. Serum Ca-125 level was elevated at $369.5 \mathrm{U} / \mathrm{ml}$ (upper limit of assay normal in our laboratory is $33 \mathrm{U} / \mathrm{ml}$ ). The peritoneal fluid Ca-125 level measured $542.0 \mathrm{U} / \mathrm{ml}$.

The patient received antituberculous treatment for 6 months with isoniazid (Nydriazid $\AA$, Squibb, Istanbul, Turkey) $300 \mathrm{mg} /$ day, ethambutol (Ethambutol ${ }^{\circledR}$, Asfarma, Istanbul, Turkey) 1,000 mg/ day and rifampicin (Rifadin ${ }^{\circledR}$, Sifar, Istanbul, Turkey) $100 \mathrm{mg} /$ day. Six months after therapy, Ca-125 levels had decreased to $34.0 \mathrm{U} / \mathrm{ml}$.

Case 2

F.S., 53 years old and 10 years postmenopausal, was admitted to the gastroenterology clinic with 2-months duration of nonspecific abdominal pain, abdominal distention and weight loss.

Physical examination showed abdominal distention due to ascites. A chest x-ray was performed which was reported as normal. Abdominal ultrasonography demonstrated ascites, hepatomegaly, irregularity of the parietal peritoneum, and normal pelvic organs. A tuberculin test was performed which showed an induration of $16 \mathrm{~mm}$ in diameter. Direct microscopic examination of the ascitic fluid obtained by a peritoneal tap did not reveal microorganisms nor acid-fast bacilli. Glucose, lactate dehydrogenase, adenosine diaminase, and total protein concentrations were $98 \mathrm{mg} / \mathrm{ml}, 162 \mathrm{U} / \mathrm{ml}, 106 \Gamma \mathrm{U} / \mathrm{ml}$ and 8.6'g/dl, respectively. Serum Ca-125 level was 402.6 $\mathrm{U} / \mathrm{ml}$. 
A laparoscopy was performed with a presumptive diagnosis of tuberculosis or intraperitoneal malignancy. The liver was covered with gray coloured granulomas of approximately $2 \mathrm{~cm}$ in size. Pelvic organs were atrophic and also covered with small granulomas. Biopsies were taken from the parietal peritoneum, uterine serosa and the liver. Histological examination of the biopsy material showed granu-lomatous inflammation and caseiñcation necrosis consistent with tuberculosis. The peritoneal fluid Ca-125 level was $630.6 \mathrm{U} / \mathrm{ml}$.

Multiagent antituberculous treatment was initiated with isoniazid $300 \mathrm{mg} / \mathrm{day}$, ethambutol 1,000 $\mathrm{mg}$ /day pyrazinamide (Farmazi-na ${ }^{\circledR}$, Deva, Istanbul, Turkey) 1,500 mg/day and rifampicin 100 $\mathrm{mg} /$ day and was continued for 12 months. Six months after therapy, the serum Ca-125 level measured $30.0 \mathrm{U} / \mathrm{ml}$.

Conclusion

Elevated serum levels of Ca-125 have been shown in patients with malignant ovarian and endometrial tumors, endometriosis, benign uterine tumors, pelvic inflammatory disease, nongynecological malignancies and physiological conditions such as pregnancy $[2,3]$.

Fig. 1. Epitheloid granuloma suggestive of tuberculosis in the specimen obtained from the ovarian capsule at laparoscopy. HE. X400.

High preoperative Ca-125 levels mostly suggest the presence of endometriosis [4] or malignancy. Although the former is more likely in a premenopausal patient complaining of pelvic pain or infertility, the latter should be considered in the differential diagnosis in an older patient presenting with ascites. As a negative chest x-ray and a borderline PPD test would not exclude its presence, tuberculosis should be included in the differential diagnosis of Ca-125 elevation particularly in countries where its prevalence is high. The expression of Ca-125 antigen by chronically inflamed tissues of mesothelial origin may account for its observed elevated levels in this disease. This hypothesis is further supported by the demonstration of declining serum levels following specific antituberculous therapy. Ca-125 may serve as a useful marker of disease activity in patients with pelvic-peritoneal tuberculosis. Furthermore, serial determinations of its serum levels may also be utilized in monitoring the treatment response to antituberculous treatment.

References

Barbieri RL, Niloff JM, Bast RC Jr, Schaetzl E, Kistner RW, Knapp RC: Elevated serum concentrations of Ca-125 in patients with advanced endometriosis. Fertil Steril 1986;45: 630634.

Malkasian GD Jr, Knapp RC, Lavin PT, Zu-rawski VR Jr, Podratz KC, Stanhope CR, Mor-tel R, Berek JS, Bast RC Jr, Ritts RE: Preoperative evaluation of serum CA 125 levels in premenopausal and postmenopausal patients with pelvic masses: Discrimination of benign from malignant disease. Am J Obstet Gynecol 1988; 159:341-346.

Niloff JM, Knapp RC, Schaetzl E, Reynolds C, Bast RC Jr: Ca-125 levels in obstetric and gynecologic patients. Obstet Gynecol 1984;64:703-707.

Yoshimura T, Okamura H: Peritoneal tuberculosis with elevated serum Ca-125 levels: A case report. Gynecol Oncol 1987;28:342-344.

61 